\title{
VALUE MANAGEMENT AND NEW Product DeVelopment
}

\author{
Palcic, I.; Semolic, B.; Polajnar, A. \& Buchmeister, B.
}

Abstract: This manuscript deals with the concept of value and customer satisfaction that is directly related to the value that a product or a service brings to customer. The concept and importance of value management is discussed, as well as product value and product functions. The final part of the paper presents a traditional value management job plan, used for value management process. The authors have modified this traditional job plan and present an improved value management methodology, used particularly for new product development.

Key words: value, value management, new product development, product function, project
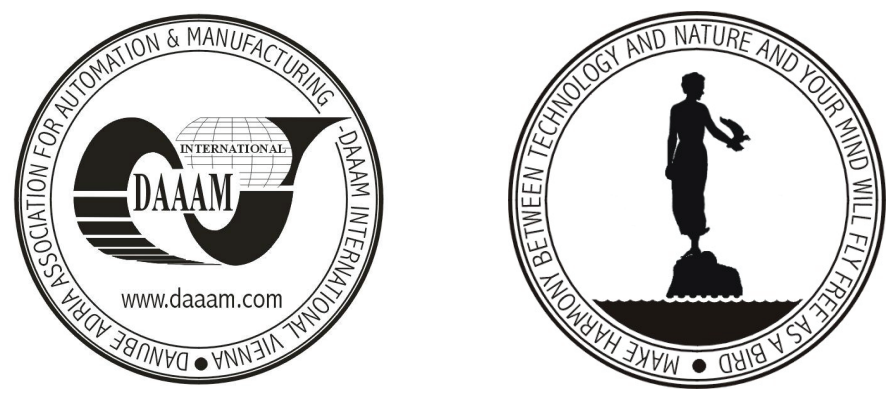

Authors' data: Ass. Prof. Palcic I.[ztok], Ass. Prof. Semolic B.[rane], Prof. Polajnar A.[ndrej], Ass. Prof. Buchmeister B.[orut], Faculty of Mechanical Engineering - Maribor, Slovenia, iztok.palcic@uni-mb.si , brane.semoli@siol.net, andrej.polajnar@uni-mb.si,borut.buchmeister@uni-mb.si

This Publication has to be referred as: Palcic, I.; Semolic, B.; Polajnar, A. \& Buchmeister, B. (2006.). Value management and new product development, Chapter 37 in DAAAM International Scientific Book 2006, B. Katalinic (Ed.), Published by DAAAM International, ISBN 3-901509-47-X, ISSN 1726-9687, Vienna, Austria DOI: $10.2507 /$ daaam.scibook.2006.37 